Document downloaded from:

http://hdl.handle.net/10251/65452

This paper must be cited as:

Lavara García, R.; Baselga Izquierdo, M.; Vicente Antón, JS.; Marco Jiménez, F. (2015). Embryo vitrification in rabbits: Consequences for progeny growth. Theriogenology. 84(5):674-680. doi:10.1016/j.theriogenology.2015.04.025.

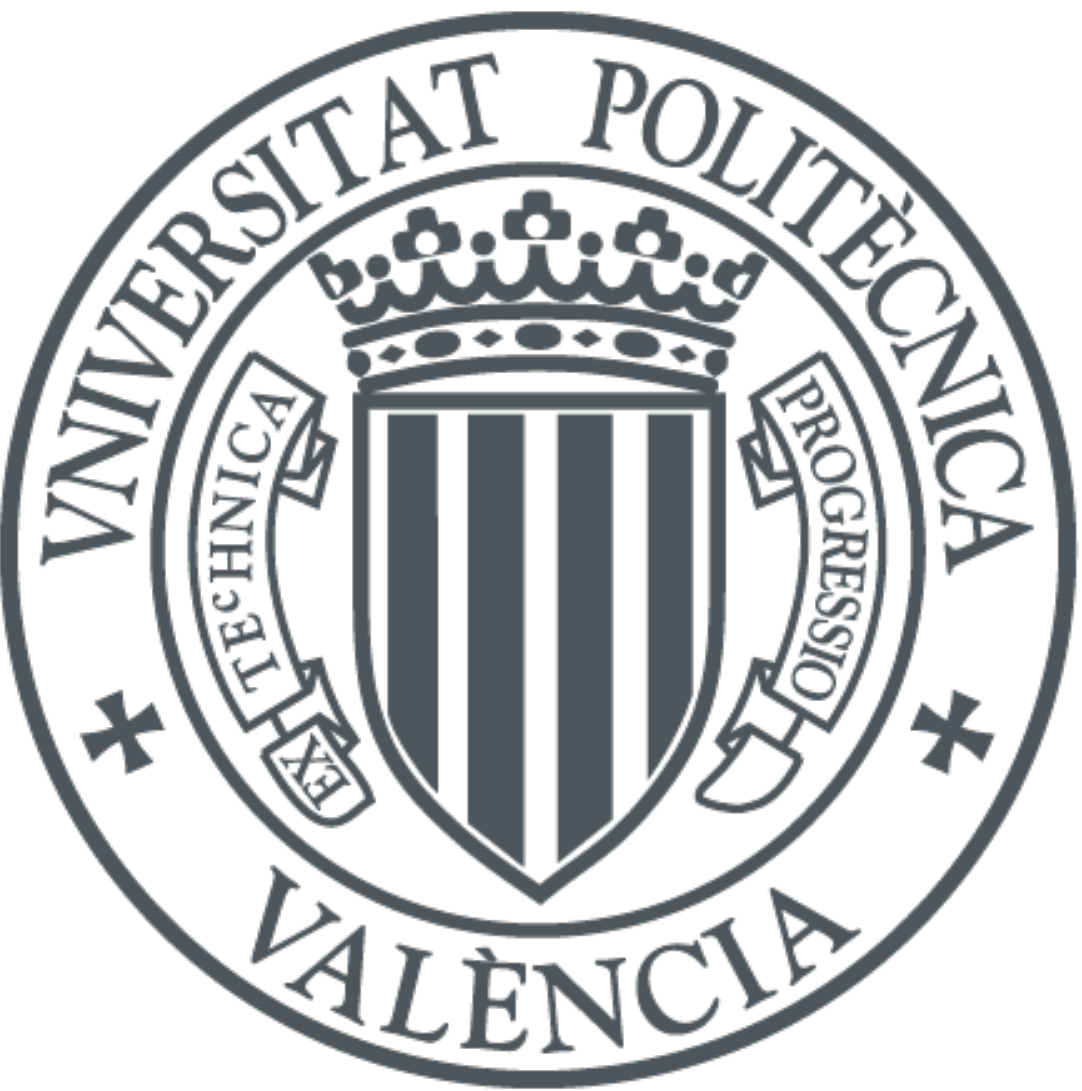

The final publication is available at

https://dx.doi.org/10.1016/j.theriogenology.2015.04.025

Copyright Elsevier

Additional Information 


\section{Embryo vitrification in rabbits: Consequences for progeny growth}

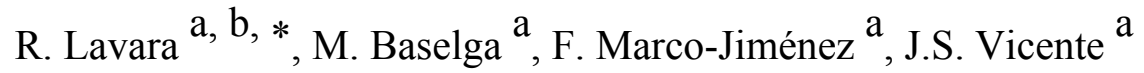

a Instituto de Ciencia y Tecnología Animal, Universitat Politècnica de València, Valencia, Spain

b INRA, UMR1388 Génétique, Physiologie et Systèmes d'Elevage, Castanet-Tolosan, France 


\section{Abstract}

The objective of this research is to examine if there are any effects of the rederivation procedures on rabbit growth pattern and on weight of different organ in adults. For this purpose, three experiments were conducted on two different groups of animals (control group and vitrified-transferred group) to evaluate the possible effect of embryo manipulation (vitrification and transfer procedures) on future growth traits. The first experiment studies body weight from 1 to 9 weeks of age from the two groups. The second experiment describes the growth curve of progeny from experimental groups and analyzes their Gompertz curve parameters, including the estimation of adult body weight. The third experiment has been developed to study if there are any differences in different organ weight in adult males from the two experimental groups. In general, the results indicate that rederivation procedures had effect on the phenotypic expression of growth traits. The results showed that rabbit produced by vitrification and embryo transfer had higher body weight in the first four weeks of age than control progeny. Results from body weight (a parameter) and $b$ parameter estimated by fitting the Gompertz growth curve did not show any difference between experimental groups. However, differences related with growth velocity ( $\mathrm{k}$ parameter of the Gompertz curve) were observed among them, showing that the control group had higher growth velocity than the vitrified-transferred group. In addition, we found that liver weight at 40th week of age exhibits significant differences between the experimental groups. The liver weight was higher in the control males than in the VF males. Although the present results indicate that vitrification and transfer pro- cedures might affect some traits related with growth in rabbits, further research is needed to assess the mechanisms involved in the appearance of these phenotypes and if these phenotypes could be transferred to the future progeny.

\section{Introduction}


Rederivation consists of establishing an animal popu- lation from cryopreserved material. This procedure is commonly used to export genetic material, estimate the genetic gain, or preserve from epizootics [1-3]. Strain rederivation from cryopreserved embryos has been used to assess the genetic improvement of quantitative traits such as prenatal survival, litter size, and growth characteristics in polytocous species such as mice, rats, and rabbits [4-7]. Nevertheless, rederivation efficiency of cryobanked embryos is related among others with the genotype of donor and recipient does, the use of superovulatory treat- ments and the cryopreservation procedure used, which induce differences in environmental effects that in fact could cause changes in embryo, fetuses, and postnatal development [8-11]. The effect of the genotype on the rederivation efficiency of cryobanked embryos in the rat, mouse, and rabbit has been observed [3,12-14]. In fact, Vicente et al. [15] reported that cryopreserved embryos from paternal rabbit lines (selected for growth characteristics) showed reduced survival rate after transfer (10\% less) compared with cryopreserved em- bryos from maternal lines (selected for reproductive char- acteristics such as litter size at birth or at weaning). One management tool used to achieve higher survival rates after thawing consists of transferring the embryos of paternal lines to recipient does from a maternal line.

Over the past decade, research works have questioned whether embryo cryopreservation and transfer procedures are neutral to survivors [16-18], as preimplantation em- bryos are removed from their natural environment and subjected to manipulation (cryopreservation and transfer procedures) which in fact affect their RNA expression [19,20], placental transcriptome, and proteome [21].

Recently, positive long-term effects of cryopreservation and transfer procedures on female reproduction have been reported in rabbits by Lavara et al. [22], with changes in epigenetic control regions caused by embryo manipulation or favorable maternal effects the most plausible explana- tions. However, little is known about the possible effect of embryo cryopreservation and transfer on postnatal growth development in mammals. Only some insights into the roles of embryo manipulation on overgrowth syndrome in ruminants [23$25]$ and on growth traits in rabbits during the first 63 days of life [26] have been reported.

The aim of this research is to examine whether there are any long-term effects of the rederivation procedures on rabbit growth pattern and on weight of different organs in 
adults.

\section{Materials and methods}

All experimental procedures involving animals were approved by the Universitat Politécnica de Valencia's Research Ethics Committee. Animals were handled ac- cording to the principles of animal care published by Spanish Royal Decree 53/2013.

\subsection{Animals}

The experiment was carried out with animals from a paternal line (line R) and from a maternal line (line V) reared at the Universitat Politécnica de Valencia. Line R is selected for growth rate between the fourth and ninth weeks of age using individual selection [27], whereas line $\mathrm{V}$ is selected with best linear unbiased prediction method- ology for litter size at weaning [28].

\subsection{Experimental design}

Briefly, morulae from line R were collected on Day 3; the embryos were then vitrified and transferred to recipient does from line $\mathrm{V}$ after thawing. Offspring from these litters form the vitrified-transferred group (VT group). On the other hand, line R progeny from naturally produced contemporaneous litters form the control group. On the day of parturition, litter size (including both live and dead kits) and the date of the birth were recorded from control and VT litters.

Three different experiments were then carried out to evaluate the possible effect of embryo manipulation (vitrification and transfer procedures) on future growth traits. The first experiment studied body weight (BW) from 1 to 9 weeks of age from the two groups.

The second experiment describes the growth curve of progeny from experimental groups and analyzes their Gompertz curve parameters, including the estimation of adult BW.

The third experiment was conducted to determine whether there are any differences in 
different organ weights in adult males from the two experimental groups.

We know that direct comparisons between progeny from the control and VT groups are not free of different postnatal maternal effects, as VT and control litters were expected to have different litter sizes at birth and were gestated and nursed by different females ( $\mathrm{R}$ or $\mathrm{V}$ females). To partially resolve this question, we included the covariate number of liveborn at birth in the analytical model, but the use of $\mathrm{V}$ females as recipients of the transferred embryos was considered an intrinsic component of the rederivation procedure.

\subsection{Rederivation procedure}

A rederivation experiment was carried out where em- bryos were previously vitrified.

\subsubsection{Embryo collection}

Embryos were obtained from adult females (line R). Females were inseminated with semen from an unrelated mature tested male from the same line to avoid an increase in consanguinity. At artificial insemination time, females were injected with $1 \mathrm{mg}$ of buserelin acetate (Hoechst Marion Roussel, Madrid, Spain) to induce ovulation. Embryos were flushed from excised oviducts and uterine horns 70 to 72 hours after artificial insemination (AI), using a medium consisting of Dulbecco's PBS (DPBS) supplemented with 0.2\% (wt/vol) BSA and antibiotics (300,000-IU penicillin G sodium; 700,000-IU penicillin G procaine; and 1250-mg dihydros- treptomycin sulfate; Penivet 1; Divasa Farmavic, Barcelona, Spain). Embryos classified as morphologically normal (clas- sified as normal when they presented correct developmental stage, homogeneous cell size and cytoplasm aspect, and intact spherical ZP and mucin coat) were vitrified.

\subsubsection{Vitrification and warming}

The vitrification procedure is described in detail elsewhere [29]. Briefly, the vitrification procedure was carried out in two steps at room temperature (approx. $20-\mathrm{C}-22-\mathrm{C}$ ). In the first step, embryos from one donor doe were placed for 2 minutes in a vitrification solution consisting of $12.5 \%$ DMSO and $12.5 \%$ of ethylene glycol in DPBS supplemented with $0.1 \%$ of BSA. In the second step, embryos were suspended for 30 seconds in a solution of 
20\% DMSO and 20\% ethylene glycol in DPBS supplemented with $0.1 \%$ of BSA. Then, em- bryos suspended in vitrification medium were loaded into $0.125-\mathrm{mL}$ plastic straws (ministraws, L’Aigle, France).

Warming was performed by horizontally placing the straw $10 \mathrm{~cm}$ from liquid nitrogen for 20 to 30 seconds; when the crystallization process began, the straws were immersed in a water bath at $20-\mathrm{C}$ for 10 to 15 seconds. The vitrification medium was removed while loading the em- bryos into a solution containing DPBS and 0.33-M sucrose for 5 minutes, followed by one bath in a solution of DPBS for another 5 minutes.

\subsubsection{Embryo transfer}

After warming, embryos were evaluated morphologically, and only embryos without damage in mucin coat or ZP were transferred into the oviducts of pseudopregnant recipient females following the procedure described by Besenfelder and Brem [30]. Ovulation was induced in recipient females with an intramuscular dose of $1 \mathrm{mg}$ of buserelin acetate 60 to 64 hours before transfer.

\subsubsection{Control progeny}

The control progeny group was obtained without embryo vitrification and transfer procedures following the common management of the selected line R. Briefly, contemporaneous control litters were produced using AI as reproductive technique. The AI was performed on receptive females using $0.5-\mathrm{mL}$ of diluted fresh semen that fulfilled the motility and morphology criteria (for more details see [31]) from individual males. Immediately after insemina- tion, ovulation was induced by an intramuscular injection of 1 mg of buserelin acetate.

\subsection{Experiment 1: Growth during the first 9 weeks}

To test for effects of rederivation procedures on offspring BW from 1 to 9 weeks of age, records of control progeny (control group, n 1/4 844 weights, from 96 rabbits) were 
compared with those that were previously vitrified and transferred (VT group, n 1/4 392 weights, from 44 rabbits).

\subsubsection{Statistical analyses}

The mixed linear model fitted for the analysis of BW at a given week was

Xijmnl 1/4 b1 BAi pb2 Aj pTm pcn peijmnl

where $\mathrm{x}_{\mathrm{ijm} m \mathrm{l}}$ is the $\mathrm{BW}$ of the animal at a given week, $\mathrm{BA}_{\mathrm{i}}$ is the covariate number of liveborn at birth and $b_{1}$ represents its regression coefficient, $A_{j}$ is the covariate age at the $\mathrm{BW}$ record and $\mathrm{b}_{2}$ its regression coefficient, $\mathrm{T}_{\mathrm{m}}$ is the fixed effect of the treatment with two levels (control and VT), $\mathrm{c}_{\mathrm{n}}$ is the random common litter effect, and eijmnl is the residual.

Differences in BW at each week between the experi- mental groups were computed as the difference in their least squares means (control_VT) and plotted as a percent of the mean of the control group.

\subsection{Experiment 2: Obtaining mature BW and parameters of growth curves}

Mature BW was estimated by fitting the Gompertz growth curve to 70 animals from two different groups (control and VT) and sexes (control-males: 15, control- females: 15; VTmales: 21, VT-females: 19), weighed weekly from 1 to 20 weeks old (140 days).

\subsubsection{Statistical analyses}

Gompertz curve parameters for each animal were esti- mated by a nonlinear regression using the NLIN procedure (SAS Inst. Inc.) [32]:

Xjm 1/4 am exp1/2_bm expð_km tP_p ejm

where $\mathrm{xjm}$ is the BW of animal $\mathrm{m}$ at age $\mathrm{t}$ (days); $\mathrm{am}, \mathrm{bm}_{\mathrm{m}}$, and $\mathrm{km}$ are the Gompertz growth curve parameters of animal $\mathrm{m}$, and ejm is the residual.

As to the meaning of parameters, a can be interpreted as the mature BW maintained 
independently of short-term fluctuations; $\mathrm{b}$ is a timescale parameter related to the initial $\mathrm{BW} ; \mathrm{k}$ is a parameter related to the rate of maturing.

The mixed linear model fitted for the analysis of Gom- pertz growth curve parameters is as follows:

Xijkl 1/4 Ti pSj pck peijkl

where $x_{i j k l}$ is the Gompertz parameter, $T_{i}$ is the fixed-effect treatment with two levels (control and VT), $\mathrm{S}_{\mathrm{j}}$ is the fixed- effect sex with two levels (male and female), $\mathrm{c}_{\mathrm{k}}$ is the random common litter effect, and eijkl represents the residual.

In addition, to improve the analytical accuracy of the estimates, the standard error on the prediction of each Gompertz parameter was included as weighting variable.

Different contrasts were computed to test the signifi- cance of the differences between the fixed effects evaluated (treatment and sex).

Gompertz 1/2ae_be_kt ${ }^{\text {kt }}$ and maturity $1 / 2 \mathrm{e}_{-}{ }^{\mathrm{be}}{ }^{\mathrm{kt}}$ _ curves for control and VT groups were represented with the aid of the "graphics" package of $\mathrm{R}[33]$.

\subsection{Experiment 3: Adult male dissection}

Adult males (40 weeks of age) from the control (n 1/4 16) and VT (n 1/4 10) groups randomly selected from 19 litters were slaughtered and dissected to obtain the following organ weights: liver, kidneys, lungs, heart, adrenal glands, spleen, and gonads, in addition to BW.

\subsubsection{Statistical analyses}

The mixed linear model fitted for the analysis of organ weight is as follows:

\section{Xijkl 1/4 b BWi pTj pck peijkl}

where $\mathrm{x}_{\mathrm{ijk}} \mathrm{kl}$ is the organ weight, $\mathrm{BW} \mathrm{i}$ is the covariate $\mathrm{BW}$ and $\mathrm{b}$ represents its regression coefficient, $\mathrm{T}_{\mathrm{j}}$ is the fixed-effect treatment with two levels (control and $\mathrm{VT}$ ), $\mathrm{ck}_{\mathrm{k}}$ is the 
random common litter effect, and eijkl represents the residual.

Differences in organ weight between the experimental groups were computed as the difference in their least squares means (control_VT).

\subsection{General remarks on statistical analyses}

All analyses with the exception of Gompertz curve estimation parameters used partial sums of squares to obtain estimates of each fixed effect independently of all model components, including the common litter random effect. Statistical analyses were carried out using the PROC MIXED procedure (SAS Inst. Inc.) [32].

\section{Results}

To test the possible effect of rederivation procedures on growth in rabbits, line $\mathrm{R}$ progeny derived from vitrification and embryo procedures was compared to line $\mathrm{R}$ progeny from naturally produced contemporaneous control prog- eny. In general, the results indicate that the rederivation procedure had an effect on the phenotypic expression of growth traits.

\subsection{Growth during the first 9 weeks}

For BW from the first until the ninth week of age, rederivation procedures had an effect over the lactation period (from 1-4 weeks, Table 1). The results showed that rabbits produced by vitrification and embryo transfer had higher BW in the first four weeks of age (Table 1, Fig. 1).

Litter size for the rederived litters, measured as the sum of both live and dead kits at birth, had an average of 5.03 kits. This was about $65 \%$ of size of naturally produced contemporaneous control litters which had a mean size of 7.8 kits. Differences in the number of liveborn affected BW from birth through 9 weeks of age, as the significance of the covariate BA indicated (Table 1).

3.2. Obtaining mature BW and parameters of growth curves

Differences between sexes were not found in any of the Gompertz curve parameters 
analyzed. In addition, mature BW (a parameter) and b parameter estimated by fitting the Gompertz growth curve did not show any difference be- tween the experimental groups (Table 2). However, differ- ences related with growth velocity (k parameter of Gompertz curve) were observed among them, revealing higher growth velocity in the control group than in the VT group (Table 2 and Fig. 2). These differences were confirmed by the maturity curves shown in Figure 3, where we see that the maturity rank order between groups changes. During the lactation period, rederived animals showed higher maturity degree than control animals, but at the end of the experimental period, this rank order changed.

\subsection{Adult male dissection}

In this work, we also study the effect of progeny origin on the weights of liver, kidneys, lungs, heart, adrenal glands, spleen, and gonads in adult males. After adjusting for BW, only liver weight exhibited significant differences between the experimental groups. The liver weight was higher in control males than in VF males (Table 3).

\section{Discussion}

Results of this study report that vitrification and transfer procedures involved in a rederivation program for rabbit embryos have long-term consequences on future rabbit growth patterns. Cryopreservation of mammalian embryos has benefitted both breeding and biomedical research in recent decades, due in part to the improvement of techniques related to vitrification, freezing-thawing processes, and transfer procedures. To this end, rabbit embryo banking has allowed the preservation and spread of genetically superior animals over different countries [34] and the possibility of evaluating the genetic gain in maternal lines [4-7] without cumulative genetic drift variance [35]. Nevertheless, it is known that these techniques induce changes in environ- mental and maternal side effects modifying the embryo gene expression and methylation pattern [19,20,36], the transcriptomic and proteomic placental profile [21], and their viability [29,37], but little is known regarding the long-term effects on the derived progeny. Some authors postulate that these procedures do 
not induce major anomalies but can lead to morphologic and behavioral features in adult mice derived from frozen embryos [16]. However, Auroux et al. [17] found a beneficial effect in longevity in adults, and Lavara et al. [22] reported a positive long-term effect on reproduction traits in rederived rabbit females from vitrified embryos, probably due to changes in epigenetic control regions related with reproductive traits.

In this study, we report differences in BW during the lactation period. These differences could be related with several aspects, among them the positive maternal effect due to the low number of litter size in VT litters compared to control litters and, probably, the embryo manipulation procedures. It is known that embryo manipulation occurring at preimplantation stages might alter future development because during this period, the embryo must undergo different events [38], affecting for instance the birth weight in human [18], or the appearance of "large offspring" phenotypes in cattle (for review see [25]), probably as a result of the impact of embryo manipulation on expression of some growthrelated imprinted genes. In fact, some re- searchers postulate that early exposure of mammals to stressful experiences could evoke some resilience to the effects of stressors [39] and, therefore, the early stress due to embryo manipulation could also act to adapt or prepare individuals for stressful environments. On the other hand, the low litter size in VT litters provides better a uterine environment for fetuses, probably causing epigenetic marks, than those provided to fetuses gestating in normal litter size [40], and this better uterine environment, jointly with the high availability of milk provided by the mother for each kit, could explain the increased growth during the lactation period in VT progeny.

Moreover, the lactation period is an important event that could influence the future development of the animal. In our case, it seems that these differences in BW during the lactation period influenced growth patterns. Growth curves can describe the entire growth process in terms of a few parameters having a biological meaning. In this study, we fitted a Gompertz curve by nonlinear regression because among the growth curves available, it fits better than other curves for describing growth of rabbits [41]. Our results reported that rederivation procedures modify the growth velocity without modifying the adult BW in males and fe- males. Similar results regarding growth velocity differences were observed 
by Cifre et al. [26], where animals coming from cryopreserved embryos showed a higher weaning weight but reduced growth rate during the fattening period (from 4-9 weeks of age). During our study period (1 to 20 weeks of age), changes in the maturity rank order between progeny groups were observed, the maturity degree being higher during the lactation period (until the 4 weeks) in VT progeny, whereas the rank order at 20 weeks changes with the control progeny being more mature than VT progeny, indicating that animals do not have the same degree of maturity at a fixed BW or the same physiological status at a constant age [42].

Therefore, the current finding of lower maturity degree in VT progeny at 20 weeks of age could explain the difference observed in adult male liver weight between both groups. Nevertheless, it must be pointed out that a recent study has reported that embryo cryopreservation and transfer pro- cedures induce changes in the placental function, altering the lipolytic-lipogenic pathway [21], which in fact could affect future organ development, as reported in a series of studies in swine $[43,44]$. In addition, several authors re- ported modifications in adult organs size due to embryo manipulation. For instance, Mahsoudi et al. [45] and Calle et al. [46] observed that manipulation of preimplantation mouse embryos resulted in altered organ sizing, and Serrano et al. [47] observed that modifications in embryo culture conditions modify the adult phenotypes, increasing the sensitivity to development of liver steatosis in females. These phenotypes could be the consequence of messenger RNA expression differences of metabolic relevant genes due to changes in methylation pattern $[48,49]$. Moreover, these epigenetic marks may be transmitted to the next two gen- erations, as Calle et al. [46] observed. It is important to bear in mind that if the phenotypes observed in this study are due to heritable epigenetic marks, special care should be taken when vitrification and embryo transfer procedures are used as tools to evaluate the response to selection in rabbit lines, as the estimated selection response could be biased.

Although the present results indicate that the rederivation process might affect some growth-related traits in rabbits, further research is needed to assess the mechanisms involved in the appearance of these phenotypes and whether these phenotypes could be transferred to the future progeny. 


\section{Acknowledgments}

This study was supported by the Generalitat Valenciana research program (Prometeo II 2014/036) and Spanish Research Projects (CICYT AGL2011-29831-C03-01; AGL201453405-C2-1-P). Lavara R. acknowledges the par- tial support received from Generalitat Valenciana under VALidp program (APOST/2014/034) and from Ministry of Economy and Competitiveness under subprogramme "Formacion posdoctoral" (FPDI-2013-16707).

\section{References}

[1] Polge C. The freezing of mammalian embryos: perspectives and possibilities. In: Elsevier Excerpta medica, editors. The freezing of mammalian embryos. North-Holland, Ciba Foundation Symposium. Published in collaboration with Elsevier Scientific Publishing Com- pany, Excerpta medica and North-Holland Publising Company, Amsterdam. 1977;52:3-19.

[2] Reetz IC, Wullenweber-Schmidt M, Kraft V, Hedrich HJ. Rederivation inbred strains of mice by means of embryo transfer. Lab Anim Sci 1988;38:696-701.

[3] Rall WF, Schmidt PM, Lin X, Brown SS, Ward AC, Hansen CT. Factors affecting the efficiency of embryo cryopreservation and rederivation of rat and mouse models. ILAR J 2000;41:221-7.

[4] García ML, Baselga M. Estimation of genetic response to selection in litter size of rabbits using a cryopreserved control population. Livest Prod Sci 2002;74:45-53.

[5] Piles M, Blasco A. Response to selection for growth rate in rabbits estimated by using a control cryopreserved population. World Rabbit Sci 2003;11:53-62.

[6] Gondret F, Larzul C, Combes S, de Rochambeau H. Carcass compo- sition, bone mechanical properties, and meat quality traits in rela- tion to growth rate in rabbits. J Anim Sci 2005;83:1526-35.

[7] LabordaP,SantacreuMA,BlascoA,MocéML.Selectionforovulation rate in rabbits: direct and correlated responses estimated with a cryopreserved control population. J Anim Sci 2012;90:3392-7.

[8] ArmbrustTA,EisenEJ.Effectofcryoprotectantandgeneticselection for body fat content on embryonic cryosurvival in mice. Theor Appl Genet 1994;88:479-85.

[9] Kauffman RD, Schmidt PM, Rall WF, Hoeg JM. Superovulation of rabbits with FSH alters in vivo development of vitrified morulae. Theriogenology 1998;50:1081-92.

[10] Glenister PH, Thornton CE. Cryoconservation-archiving for the future. Mamm Genome 2000;11:565-71.

[11] Mehaisen GMK, Vicente JS, Lavara R, Viudes de Castro MP. Effect of eCG dose and ovulation induction treatments on embryo recovery and in vitro development postvitrification in two selected lines of rabbit does. Anim Reprod Sci 2005;90:175-84.

[12] Pomp D, Eisen EJ. Genetic control of survival of frozen mouse em- bryos. Biol Reprod 1990;42:775-86.

[13] Lavara R, Baselga M, Vicente JS. Does storage time in Ln2 influence survival and pregnancy outcome of vitrified rabbit embryos? Theriogenology 2011;76:652-7. 
[14] Mochida K, Hasegawa A, Li M-W, Fray MD, Kito S, Vallelunga JM, et al. High osmolality vitrification: a new method for the simple and temperature-permissive cryopreservation of mouse embryos. PLoS One 2013;8:e49316.

[15] Vicente JS, Viudes de Castro MP, García ML, Baselga M. Effect of rabbit line on a program of cryopreserved embryos by vitrification. Reprod Nutr Dev 2003;43:137-43.

[16] Dulioust E, Toyama K, Busnel MC, Moutier R, Carlier M, Marchaland C, et al. Longterm effects of embryo freezing in mice. Proc Natl Acad Sci U S A 1995;92:589-93.

[17] Auroux M, Cerutti I, Bucot B, Loeuillet A. Is embryo-cryopreservation really neutral? A new long-term effect of embryo freezing in mice: protection of adults from induced cancer according to strain and sex. Reprod Toxicol 2004;18:813-8.

[18] Nelissen EC, Van Montfoort AP, Coonen E, Derhaag JG, Geraedts JP, Smits LJ, et al. Further evidence that culture media affect perinatal outcome: findings after transfer of fresh and cryopreserved em- bryos. Hum Reprod 2012;27:1966-76.

[19] Saenz-de-Juano MD, Marco-Jiménez F, Peñaranda DS, Joly T, Vicente JS. Effects of slow freezing procedure on late blastocyst gene expression and survival rate in rabbit. Biol Reprod 2012;87:1-9.

[20] Vicente JS, Saenz-De-Juano MD, Jiménez-Trigos E, Viudes-De- Castro MP, Peñaranda DS, Marco-Jiménez F. Rabbit morula vitrifi- cation reduces early foetal growth and increases losses throughout gestation. Cryobiology 2013;64:321-6.

[21] Saenz-de-Juano MD, Marco-Jimenez F, Schmaltz-Panneau B, Jimenez-Trigos E, Viudes-de-Castro MP, Peñaranda DS, et al. Vitrification alters rabbit foetal placenta at transcriptomic and proteomic level. Reproduction 2014;147:789-801.

[22] Lavara R, Baselga M, Marco-Jiménez F, Vicente JS. Long-term and transgenerational effects of cryopreservation on rabbit embryos. Theriogenology 2014;81:988-92.

[23] Walker SK, Hartwich KM, Seamark RF. The production of unusually large offspring following embryo manipulation: Concepts and challenges. Theriogenology 1996;45:11120.

[24] Young LE, Sinclair KD, Wilmut I. Large offspring syndrome in cattle and sheep. Rev Reprod 1998;3:155-63.

[25] Sinclair KD, Young LE, Wilmut I, McEvoy TG. In-utero overgrowth in ruminants following embryo culture: lessons from mice and a warning to men. Hum Reprod 2000;15:68-86.

[26] Cifre J, Baselga M, Gómez EA, García ML. Effect of embryo cryo- preservation techniques on reproductive and growth traits in rab- bits. Ann Zootech 1999;48:15-24.

[27] Estany J, Camacho J, Baselga M, Blasco A. Selection response of growth rate in rabbits for meat production. Gent Sel Evol 1992;24:527-37.

[28] Estany J, Baselga M, Blasco A, Camacho J. Mixed model methodology for the estimation of genetic response to selection in litter size of rabbits. Livest Prod Sci 1989;21:67-75.

[29] Vicente JS, Viudes de Castro MP, García ML. In vivo survival rate of rabbit moruale after vitrification in a medium without serum pro- tein. Reprod Nutr Dev 1999;39:657-62.

[30] Besenfelder U, Brem G. Laparoscopic embryo transfer in rabbits. J Reprod Fertil 1993;99:53-6.

[31] Lavara R, Mocé E, Lavara F, Viudes de Castro MP, Vicente JS. Do parameters of seminal quality correlate with the results of on-farm inseminations in rabbits? Theriogenology 2005;64: 1130-41.

[32] SAS statistical software package, version 9.2 (SAS Institute, Cary, NC). 
[33] R Core Team. R: a language and environment for statistical computing. R Foundation for Statistical Computing, Vienna, Austria. 2014; URL http://www.R-project.org/.

[34] García ML, Blumeto O, Capra G, Vicente JS, Baselga M. Vitrified embryos transfer of two selected Spanish rabbit lines to Uruguay. In: 7th World Rabbit Congress, Vol A. Spain: Published by Uni- versidad Politecnica de Valencia; 2000. p. 139-42.

[35] Smith Ch. Use of stored frozen semen and embryos to measure genetic trends in farm livestock. Z für Tierzüchtung Züchtungsbio- logie Bd 1977;94:119-27.

[36] Stojanov T, O'Neill C. In vitro fertilization causes epigenetic modi- fications to the onset of gene expression from the zygotic genome in mice. Biol Reprod 2001;64:696-705.

[37] Mocé ML, Blasco A, Santacreu MA. In vivo development of vitrified rabbit embryos: effects on prenatal survival and placental devel- opment. Theriogenology 2010;73:704-10.

[38] Zernicka-Goerz M, Morris SA, Bruce AW. Making a firm decision: multifaceted regulation of cell fate in the early mouse embryo. Nat Rev Genet 2009;10:467-77.

[39] Meek LR, Dittel PL, Sheehan MC, Chan JY, Kjolhaug SR. Effects of stress during pregnancy on maternal behavior in mice. Physiol Behav 2001;72:473-9.

[40] Atchley WR, Logsdon T, Cowley DE. Uterine effects, epigenetics and postnatal skeletal development in the mouse. Evolution 1991;45: 891-909.

[41] Blasco A, Gómez E. A note on growth curves of rabbit lines selected on growth rate or litter size. Anim Prod 1993;57:332-4.

[42] Taylor SC. Use of genetic size-scaling in evaluation of animal growth. J Anim Sci 1985;61:118-43.

[43] Town S, Patterson J, Pereira C, Gourly G, Foxcroft GR. Embryonic and fetal development in a commercial dam-line genotype. Anim Reprod Sci 2004;85:301-16.

[44] Town S, Putman C, Turchinsky J, Dixon W, Foxcroft GR. Number of conceptuses in utero affects porcine fetal muscle development. Reproduction 2004;128:443-54.

[45] Mahsoudi B, Li A, O'Neill C. Assessment of the long-term and transgenerational consequences of perturbing preimplan- tation embryo development in mice. Biol Reprod 2007;77: 889-96.

[46] Calle A, Miranda A, Fernandez-Gonzalez R, Pericuesta E, Laguna R, Gutierrez-Adan A. Male mice produced by in vitro culture have reduced fertility and transmit organomegaly and glucose intolerance to their male offspring. Biol Reprod 2012; 87:1-9.

[47] Serrano A, Decara JM, Fernández-González R, López-Cardona AP, Pavón FJ, Orio L, et al. Hyperplastic obesity and liver steatosis as long-term consequences of suboptimal in vitro culture of mouse embryos, Biol Reprod 2014;91:30,1-14.

[48] Schumacher A, Doerfler W. Influence of in vitro manipulation on the stability of methylation patterns in the Snurf/Snrpn-imprinting region in mouse embryonic stem cells. Nucl Acids Res 2004;32: 1566-76.

[49] Fernandez-Gonzalez R, Ramirez MA, Pericuesta E, Calle A, Gutierrez- Adan A. Histone modifications at the blastocyst Axin $(\mathrm{Fu})$ locus mark the heritability of in vitro culture-induced epigenetic alterations in mice. Biol Reprod 2010;83:720-7. 



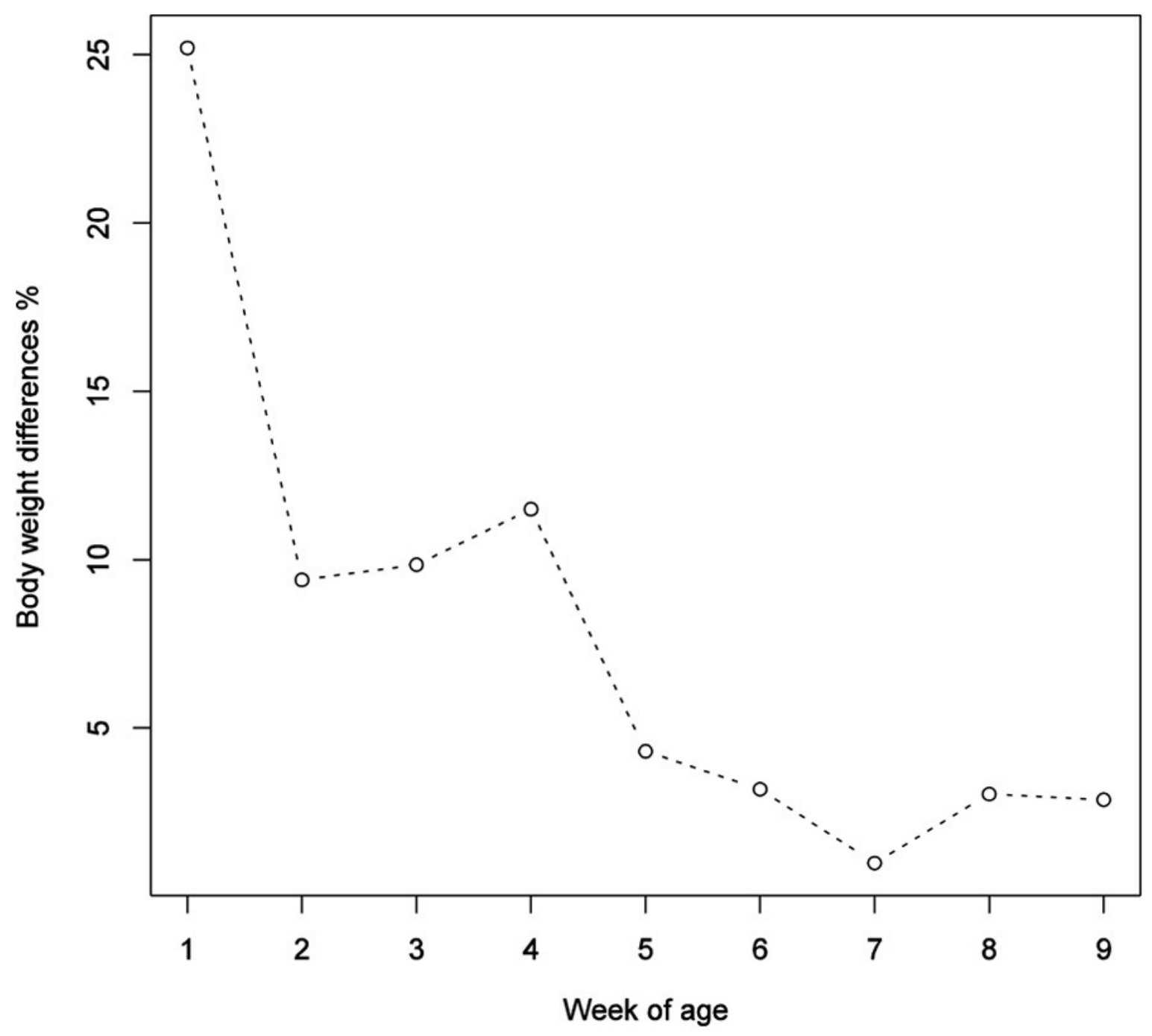




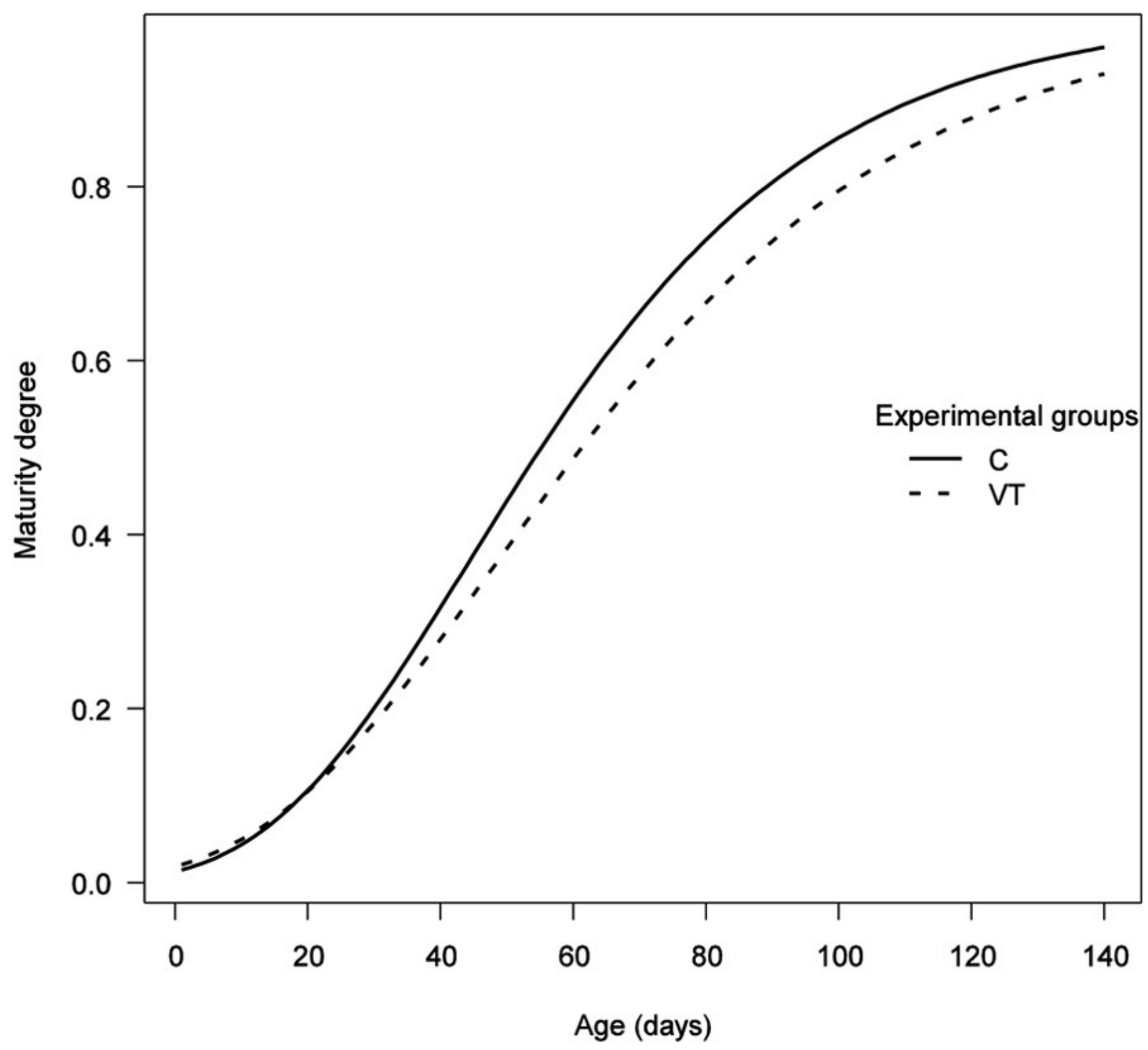




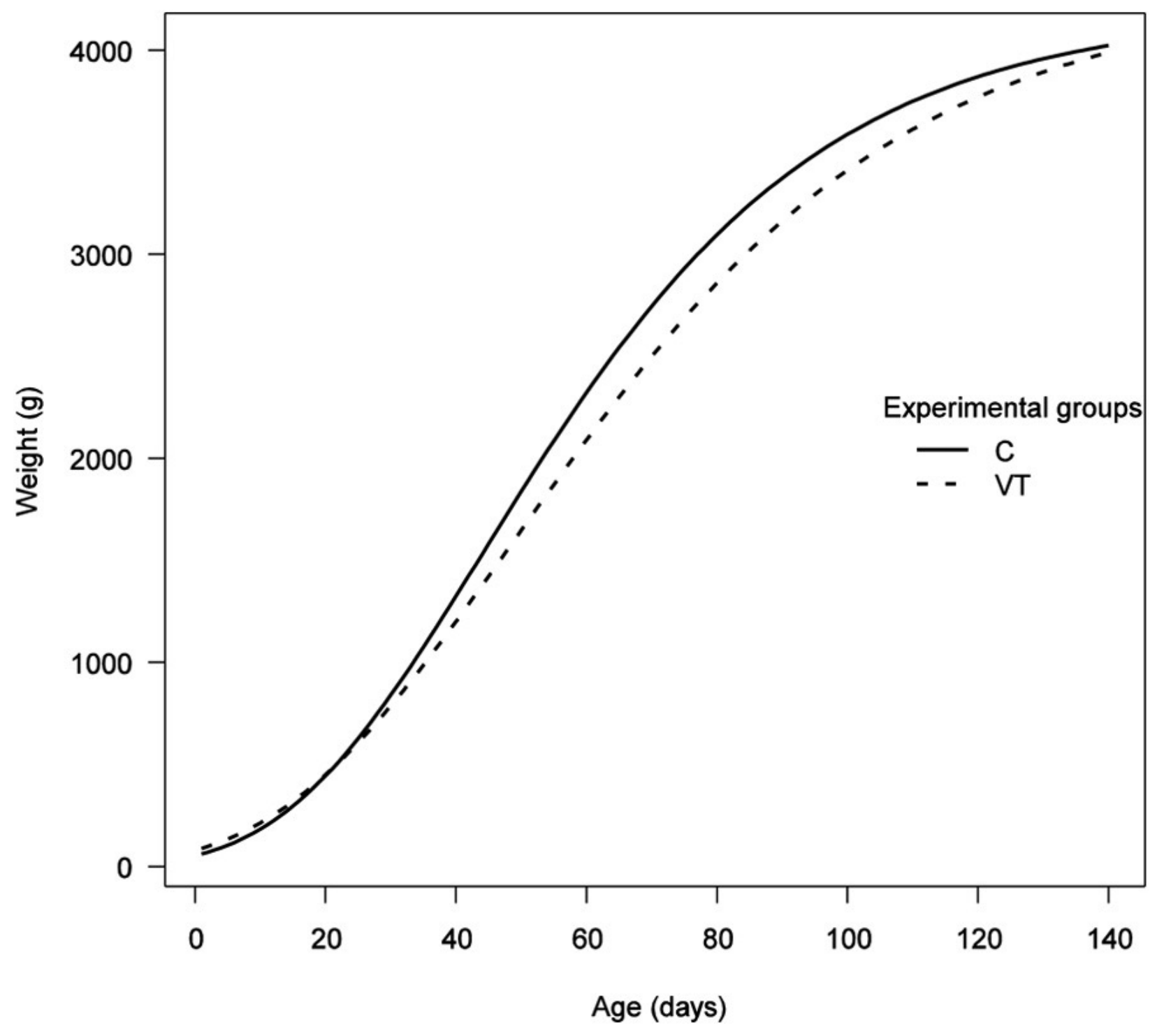




\section{Table 2}

Least-square means and standard errors of Gompertz curve parameters from different groups.

\begin{tabular}{lll}
\hline \multirow{2}{*}{$\begin{array}{l}\text { Gompertz } \\
\text { parameter }\end{array}$} & Group \\
\cline { 2 - 3 } & $\mathrm{C}(\mathrm{n}=30)$ & $\mathrm{VT}(\mathrm{n}=40)$ \\
\hline $\mathrm{a}$ & $4190.62 \pm 131.48$ & $4290.98 \pm 105.12$ \\
$\mathrm{~b}$ & $4.18 \pm 0.14$ & $4.01 \pm 0.12$ \\
$\mathrm{k}$ & $0.0334 \pm 0.0011^{\mathrm{a}}$ & $0.0286 \pm 0.0008^{\mathrm{b}}$ \\
\hline
\end{tabular}

$\mathrm{n}$ represents the number of samples.

a,b Values in the same row with different superscript are significantly different $(\mathrm{P}<0.05)$.

Abbreviations: C, control; VT, vitrified transferred. 


\section{Table 3}

Results from dissection analyses of adult males.

\begin{tabular}{llr}
\hline Component (weight, g) & \multicolumn{2}{l}{ Group } \\
\cline { 2 - 3 } & $\mathrm{C}(\mathrm{n}=16)$ & $\mathrm{VT}(\mathrm{n}=10)$ \\
\hline Liver & $98.87 \pm 2.88^{\mathrm{a}}$ & $83.64 \pm 3.84^{\mathrm{b}}$ \\
Kidney & $21.69 \pm 0.55$ & $20.79 \pm 0.74$ \\
Heart & $21.40 \pm 1.31$ & $20.73 \pm 1.74$ \\
Lungs & $10.73 \pm 0.45$ & $10.04 \pm 0.61$ \\
Spleen & $1.35 \pm 0.09$ & $1.27 \pm 0.12$ \\
Gonads & $6.44 \pm 0.49$ & $7.21 \pm 0.66$ \\
Adrenal glands & $0.53 \pm 0.05$ & $0.46 \pm 0.06$ \\
\hline
\end{tabular}

$\mathrm{n}$ represents the number of samples.

${ }^{\mathrm{a}, \mathrm{b}}$ Values in the same row with different superscript are significantly different $(\mathrm{P}<0.05)$.

Abbreviations: C, control; VT, vitrified transferred. 